\title{
El movimiento de Jesús después de su resurrección y antes de la Iglesia. Claves hermenéuticas para interpretar los Hechos de los apóstoles (I)
}

\author{
Pablo Richard, \\ Departamento Ecuménico de Investigaciones, \\ San José, Costa Rica.
}

\section{Introducción}

El libro de los Hechos de los apóstoles fue escrito entre los años 80 y 90 , posiblemente en Efeso. La tradición reconoce como autor del tercer evangelio y de los Hechos a Lucasi. El contenido del libro cubre casi completamente el período Ilamado comúnmente período apostólico (del año 30 al 70): comienza con la resurrección de Jesús (año 30) y termina con la actividad de Pablo en Roma durante dos años (del 58 al 60).

El perído en el cual Lucas escribe los Hechos es conocido como período sub-apostólico (70-135). Es el perfodo de la organización de la Iglesia, en el que se institucionalizan sus diferentes modelos2. Lucas busca con su libro de los Hechos reconsiruir el período que va desde la resurrección de Jesús hasta la organización de las iglesias, período normalmente olvidado en la tradición, pues, en el innaginario colectivo de los cristianos, la fundación y organización de la Iglesia aparecen directamente ligadas al Jesús histórico. Jesús y la Iglesia aparecen unidos históricamente. Desde esta perspectiva, rescatar el libro de los Hechos es justamente rescatar ese período histórico de treinta años, que va de la resurrección de Jesús a la organización de las iglesias.

1. Para cuestiones introductorias véase R. Aguirre y A. Rodríguez, Evangelios sinópricos y Hechos de los Apóstoles, Estella, 1994.

2. Véase R. Brown. Las iglesias que los apóstoles nos dejaron, Bilbao, 1986. 
El evangelio de Lucas y los Hechos de los apóstoles tienen un mismo autor y constituyen una sola obra, y es posible que en su primera composición formaran un solo libro. En ese caso, el evangelio Lerminaría en 24, 49 y Hechos comenzaría en I, 6. Cuando se separaron las dos obras se habrían agregado los vv. 5053, al final del evangelio, y los vv. 1-5 al comienzo de los Hechos. El prólogo que tenemos en Lucas 1, 1-4 es para toda la obra Lucas-Hechos. La obra comienza en el templo de Jerusalén con el anuncio del nacimiento de Juan bautista y termina en Roma con la predicación del reino de Dios, realizada por Pablo con toda valentra y sin estorbo alguno. Toda la obra es un evangelio y tiene una profunda coherencia teológica, si bien hay un progreso histórico y teológico desde el comienzo hasta el final. Aquí veremos solamente la segunda parte de este gran evangelio, que fue llamada desde antiguo "Hechos de los apóstoles".

El libro de los Hechos reconstruye el movimiento de Jesús después de su resurrección y antes de la institucionalización de las iglesias (ocurrida después del año 70). Este movimiento tiene, según los Hechos, tres características: es un movimiento animado por el Espírilu Santo, es un movimiento misionero y tiene como estructura básica a misioneros itinerantes y a pequē̄as comunidades domésticas.

El tiempo después de la resurrección de Jesús es el tiempo privilegiado del Espíritu. Eso es justamente lo que rescatan los Hechos y por eso muchos lo han llamado el "Evangelio del Espíritu Santo". El movimiento de Jesús también en los Hechos es un movimiento esencialmente misionero, cuyas dos caracteristicas fundamentales aparecen resumidas en 1, 8: "recibirán la fuerza del Espíritu Santo y serán mis testigos en Jerusalén, en toda Judea y Samaría y hasta los confines de la tierra". El movimiento de Jesús, por lo tanto, antes de institucionalizarse como lglesia, fue un movimiento del Espíritu y un movimiento misionero. La experiencia del Espíritu y de la misión son, entonces, históricamente anteriores a la Iglesia. Primero es el Espíritu y la misión, luego viene la institucionalización de las iglesias.

Los misioneros itinerantes y las primeras comunidades domésticas, como características básicas del movimiento, son realidades complementarias y se necesitan mutuamente. Las comunidades son una realidad decisiva según los $\mathrm{He}$ chos, como lo muestra un recorrido por el libro. En él se habla de la primera comunidad apostolica (1, 12-14), de que pentecostés tiene lugar en una casa (2, $1-4)$, de la comunidad ideal después de pentecostés $(2,42-47)$. La comunidad permite resistir la persecución $(4,23-31)$, las comunidades son perseguidas por las casas $(8,3)$. Hay una comunidad de helenistas $(6,1-6)$, se menciona una comunidad en casa de Cornelio (10, 1-48), otra comunidad en casa de María, la madre de Juan Marcos (12, 12-17), otra comunidad cristiana en Antioquía (13. 1-4 y 14, 27). Pablo runda pequeñas comunidades en las casas: en Filipo ( 16 , 1 1-40), en Tesalónica (17, 1-9) y en Corinto (18, 1-11). En Tróade, la comuni- 
dad vive en una casa la experiencia de la palabra, de la cucarislía y de la resurrección $(20,7-12)$. La palabra tiene poder para construir la comunidad (20, 32). En Cesarea hay una comunidad de mujeres profetas (21, 8-14); en Jerusalén, Pablo llega a la casa-comunidad de Mnasón (21, 17-20). Y el libro termina con la mención de la úllima comunidad de Pablo en Roma (28, 30-31) ’.

Hoy dia hay que volver a leer los Hechos para recuperar esa dimensión del Espíritu y de la misión, anterior a la instilucionalización de la Iglesia, y para recuperar tambićn la primera organización del movimiento de Jesús en pequeñas comunidades y con misioneros itinerantes. Esa fue la experiencia originaria y fundante, que hizo posible la evangelización y la inculturación del evangelio.

Lo importante ahora es apropiamos del texto de los Hechos, y para ello es de gran utilidad presentar su estructura literaria global. Proponemos aquí una esIructura que nos permita hacer una primera lectura organizada del texto:

\section{Introducción: 1, 1-11}

A. Retomando el pasado: 1, 1-5

(Agregado cuando se separaron los dos libros)

Resumen del evangelio: vv. 1-2

Los dias de la resurrección: vv. 3-5

B. Introducción a los Hechos de los apóstoles: 1, 6-II

(Conlinúa el discurso de Lc 24, 49)

Esirategia de Jesús resucitado: vv. 6-8

Exaltación de Jesús resucitado: vv. 9-11

I. La Iglesia de Jerusalén: 1, 12 • 5, 42 (años 30-32)

La comunidad de los creyentes hebreos dirigida por los doce apóstoles

A. Conslitución de la comunidad: I, $12-2,47$

Sumario: 1, 12-14: la comunidad antes de pentecostés

Narración: 1, 15-26: constitución de los doce

Narración: 2, 1-41: pentecostés

Sumario: 2, 42-47: la comunidad después de pentecosićs

3. Véase P. Richard, Commidades ectesiales de base. Fundamennos bíblicos, San José, 1996. 
B. Manifestación de la comunidad en Jerusalén: 3, 1 - 4, 31

Narración en cuatro actos:

1. Curación de un tullido: $3,1-10$

2. Anuncio de la resurrección: 3, 11-26

3. Represión: 4, 1-22

4. Reunión de la comunidad: 4, 23-31

A. Consolidación de la comunidad: 4, 32-5, 16

Sumario: 4, 32-35

Narración: 4, 36-37: Bernabé

Narración: 5, 1-11: Ananías y Safira

Sumario: 5, 12-16

B. Reconocimiento de la comunidad: 5,17 - 41

Narración en cuatro actos:

1. Prisión de los apósioles y liberación: 5, 17-21a

2. Convocación del sanedrín y testimonio de los apóstoles: 5, 2lb-33

3. Intervención de Gamaliel y acuerdo con el sanedrín: 5, 34-39

4. Represión de los apóstoles y libcración: 5, 40-41

Sumario conclusivo: 5,42 :

Los apóstoles enseñan y anuncian cada día en el templo y por las casas

I. De Jerusalén a Antioquía: 6, 1 - 15, 35 (años 32-48)

La comunidad de los helenistas y el inicio de la misión fuera de Jerusalén

A. Hechos de los helenistas: 6, 1 - 8, 40

(Constitución del grupo de los siele helenistas)

Asamblea en Jerusalén: elección de los siete helenistas: 6, 1-7

Hechos de Esteban: 6, 8 - 7, 60

Dispersión del grupo de los helenistas: 8, 1-4

Hechos de Felipe: 8, 5-40

B. Hechos de Saulo: 9, 1-31

C. Hechos de Pedro: 9, 32 - 11, 18

En Lida y Jope: 9, 32-43

Conversión de la casa de Cornelio: 10, 1 - 48

Defensa de Pedro ante "los de la circuncisión": 11,118

A. Hechos de los helenistas: 11, 19-30

(Los helenistas fundan la Iglesia en Anlioquía)

Misión de los dispersados-conversión de griegos en Antioquia: vv.19-21 
Misión de Bernabé desde Jerusalén a Antioquía: vv. 22-24

La comunidad de los cristianos en Antioquía: vv 25-26

C. Hechos de Pedro: 11, 27 - 12, 25

[Misión de Bernabé y Saulo en Jerusalén: 11, 27-30]

Muerte de Santiago apóstol, hermano de Juan: vv. 1-2

Prisión y liberación de Pedro: vv. 3-17

Pedro salió y marchó a otro lugar

Muerte de Herodes: vv. 18-23

Sumario: la palabra de Dios crecía y se multiplicaba: v. 24

[Bernabé y Saulo, junto con Juan Marcos, regresan a Anlioquía: v.25]

A. Hechos de los helenistas: 13,1 - 14, 28

(Misión de la comunidad de Antioquía)

Asamblea de la comunidad de Antioquía y envío: vv. 1-3

Misión de la Iglesia de Antioquía: 13, 4 - 14, 26

Llegada y asamblea de la comunidad de Antioquía: 14, 27-28

A. Hechos de los helenistas: 15, 1-35

(Asamblea de Jerusalén confirma a la comunidad de Antioquía)

Antioquía: conflicto con algunos de Judea - misión a Jerusalén: vv, 1-4

Jerusalén: asamblea de los apóstoles y presbíleros: vv. 5 - 29

Introducción: conflicto y convocación a la asamblea: vv. -6

Discurso de Pedro: vv. 7-12

Discurso de Santiago: vv.13-21

Conclusión: acuerdos de la asamblea: vv.22-29

Antioquia: la comunidad acoge a los delegados de Jerusalén y la carta apos-

tólica: vv. 30-35

\section{De Antioquía a Roma: 15, 36 - 28, 31 (años 48-60)}

A. Los viajes misioneros de Pablo: 15, 36 - 19, 20 (años 48- 55)

1. Pablo entre la ley y el Espíritu: $15,36-16,10$

2. Misión en la ciudad de Filipos: $16,11-40$

3. Misión en la ciudad de Tesalónica: 17, 1-9

4. Misión de Pablo y Silas en Berea: 17, 10-15

5. Pablo en Atenas: 17, 16-34

6. Misión en la ciudad de Corinto: 18, 1 - 18a

7. Misión en la ciudad de Efeso: 18, 18b - 19, 20

B. Subida a Jerusalén y viaje a Roma: $19,21-28,31$

1. Pablo toma la decisión de ir a Jerusalén y Roma: 19, 21-22

2. Revuelta de los orfebres en Efeso: 19, 23-40

3. Desde Efeso subida a Jerusalén: $20,1-21,15$ 
4. Pablo en Jerusalén: 21, 16 - 23, 35 (año 56)

5. Pablo en Cesarea: 24, 1 - 26, 32 (años 56-57)

6. Pablo camino a Roına: 27, I - 28, 14a (año 58)

7. Pablo en Roma: 28, 14b-31 (años 58-60)

\section{Introducción: 1, 1-11}

\section{Algunas claves de interpretación}

Los primeros cinco versículos fueron agregados cuando la obra de Lucas fue dividida en dos. Era necesario resumir el evangelio (vv. 1-2) y volver a introducir el segundo volumen que posteriormente se llamaría Hechos de los apóstoles (vv. 3-5). Lucas retoma en 1 , I la referencia a Té́filo que puso al comienzo de su evangelio ("ilustre Teófilo", Lc 1, 3). Este Teófilo pudo haber sido una persona concrela (era costumbre dedicar una obra a personajes ilustres) o puede ser un nombre simbólico para designar a sus interlocutores. Te6filo significa "amigo de Dios" y podría referirse a los futuros catequistas y evangelistas para quienes Lucas escribe este tratado de enseñaza superior. El hecho de agregarlo aquf, después de separarse la obra lucana en dos, refuerza la idea de que "Téfilo" es una designación simbólica general. Según eso, todos los que estudiamos este libro somos "Té́filos". Para nosotros se escribieron los Hechos de los apóstoles.

El contenido del evangelio, que Lucas resume aqui, es "todo lo que Jesús comenzó a hacer y enseñar... hasta el día que fue llevado al cielo". La expresión "comenzó" deja entender que Jesús continúa su acción y enseñanza después de ser arrebatado al cielo. El texto destaca que antes de ser llevado al cielo dio "instrucciones por medio del Espíritu Santo a los apóstoles que había elegido". Tenemos entonces dos períodos: la acción y enseñanza de Jesús antes de su ascensión (narradas en el evangelio) y la acción y enseñanza de Jesús después de su ascensión (narradas en los Hechos). El evangelio es sólo el comienzo, nosolros vivimos la continuación iniciada por el relato de los Hechos. Los apóstoles aseguran la continuidad entre el tiempo del evangelio y el comienzo del tiempo de la Iglesia. Los vv. 3-5 retoman el final del evangelio de Lucas (cap. 24), pero ahora con un sentido diferente: en el evangelio la resurrección es el fín de la vida de Jesús; en los Hechos es el comienzo de la misión.

En el evangelio, el tiempo después de la resurrección es un solo día; en los Hechos son 40 días. Lucas separa la resurrección de la ascensión de Jesús y crea ahora este tiempo intermedio de $\mathbf{4 0}$ días. En el evangelio, Jesús, antes de comenzar su ministerio, es conducido por el Espíritu al desierto y es tentado por el 
diablo durante 40 días (Lc 4, I-2); ahori, lambién los apóstoles, antes Je comenzar su testimonio, tienen ese mismo liempo de 40 dias con Jesús vivo en medio de ellos. De este tiempo, el texlo deslaca dos cosis: que Jesús está vivo y quc les habla del reino de Dios. Los 40) Jias es una cifra simbólica para designar un liempo largo de preparación, de discernimiento, de crisis y de tentación. Posiblemente, Lucas pone estos $\mathbf{4 0}$ dias al comienzo de los Hechos para sugerir que lambién la comunidad de los apóstoles vivió un tiempo de tentación y discemimiento antes de comenzar el liempo nucvo de la misión. La crisis giró, posiblemente, en torno al reino de Dios como realidad posterior a la resurreción de Jesús. La pregunta en el v. 6 relleja csa crisis, como lambićn la aclitud de los Jos discipulos de Emaús antes de su encuentro con Jesús (Lc 24, 13-24).

En el v. 3 se dice que Jcsús se presentó vivo a los apóstoles, ahora en el v. 4 Jesús da una orden a los apóstoles: no ausentarse de Jerusalén y esperar la promesa del Padre. Esta orden la da "micntras comía con ellos". En el evangelio (Lc 24, 41-43), Jesús también come con ellos, como prueba de su corporeidad, de su pertenencia como resucitado a nucstra historia. Ahora, la comida significa, posiblemente, la comensalidad como signo de la comunidad cristiana. En torno a una mesa para comer, la comunidad hace la experiencia de Jesús resuciado en la "fracción del pan". Al final del evangelio, el comer expresa la corporeidad del resucilado; ahora, expresa la presencia del resuciado en la comunidad. Por lo demás, la relación entre comida en común y rcino de Dios es frecucnle en la tradición sinóplica.

La orden que Jesús da a los apóstoles en el v. 4 exige pasividad total: no ausentarse de la ciudad y aguardar. En Lucas 24, 49 ocurre lo mismo: permanecer en la ciudad (con la connolación de csperar sin hacer nada). La permanencia y espera pasiva deben durar "hasta que sean bautizados en el Espíritu Santo" (Hech 1, 5) o "hasta que sean revestidos del poder de lo alto" (Le 24, 49). Lucas se está aquí refiriendo claramente a pentecostés, no a la ascensión, lo cual es importante para entender el sentido de la ascensión (1, 9-11) y de la elección de Matias (1, 15-26), como veremos mús adelantc.

El "bautismo en el Espírilu Santo" está al comienzo de la misión de los apóstoles, así como el bautismo de Jesús en el Jordán está al comienzo de su ministerio. Ya Juan bautista había anunciado cste baulismo en el Espírilu Santo, que sería obra del mismo Jesús (Le 3, 16). Penlecostés es este bautismo en el Espíritu Santo, realizado por Jesús resucitado y exaltado. El bautismo no es aquí lodavia un rito cristiano, sino la inaugurición del tiempo del Espíritu, del cual lodo el libro de los Hechos dará testimonio. Pentecostés inaugura una experiencia histórica continua del Espíritu, que se repetirá en la primera comunidad cristiana $(4,31)$ y también en la casa de Cornelio, incluso antes de recibir el rito del bautismo. Los samaritanos recibirán el Espírilu después del bautismo ( 8 , 14-17). 
Si aceptamos la hipótesis que cl evangelio y los Hechos formaban una sola obra, el relato que se inicia en los Hechos 1, 6 continúa el relalo del evangelio que terminó en Lucas 24, 49. El lexto seguido se leería así:

Miren, yo voy a enviar sobre usiedes la promesa de mi Padre. Ustedes permanezcan en la ciudad hasta que sein revestidos del poder de lo alto (LC 24, 49). Los que eslaban reunidos le preguntaron: Señor, ies ahora cuando vas a restablecer el reino de Isracl? (Hech 1,6 ).

Es importanle pregunlarse quiénes eran esos "que estaban reunidos". En Lucas 24 se dice explícitamente que las mujeres anuncian el hecho del sepulcro vacío "a los once y a todos los demás" $(24,9)$ y que los discípulos de Emaús vuelven a Jerusalén y encuentran reunidos "a los once y a los que estaban con ellos". El texto nos dice claramente quiénes están con los once:

(1) "María Magdalena, Juana y María la de Santiago y las demás que eslaban con ella" ( $L C 24,10)$.

(2) Los dos discípulos que parten del grupo camino a Emaús $(L c 24,13)$ y que relornan a él (Le 24, 33).

(3) Junto con los once, que son nombrados por su nombre, estaban "algunas mujeres, María la madre de Jesús y sus hermanos" (Hech 1, 14).

(4) Todos son llamados "galileos" (Hech 1, 11).

Tenemos aqui una clave muy importinle de interpretución: el grupo reunido el día de la resurrección es un grupo galileo, compuesto por los once, por un grupo de mujeres (donde destacan María Magdalena y María, la madre de Jesús), los hermanos de Jesús (entre los cuales destaca Santiago, a partir del capitulo 12 de los Hechos) y los dos discípulos de Emaús. Esle es el grupo al que las mujeres anuncian el hecho del sepulcro vacio y al que se aparece Jesús resucitado. A este grupo, Jesús abre su inteligencia para que comprendan las Escrituras y a todos ellos les promete que serán revestidos del poder de lo alto (Le 24). Y a este mismo grupo Jesús dice: "Ustedes recibirán la fuerza del Espíritu Santo... y serán mis lestigos" (Hech 1, 8). Ante ellos, Jesús es elevado al cielo, y a ellos, los dos hombres vestidos de blanco anuncian el retorno de Jesús (I, 9-1I). Adelantándonos un poco, también descubrimos que es el mismo grupo, con Pedro a la cabeza, el que elige, en una asamblea, a Malías, como sustiluto de Judas, donde se especifica además que el grupo era de 120 personas $(1,15-26)$. Y es finalmente el mismo grupo el que está reunido en una casa el día de pentecostés y el que recibe el Espiritu Santo y habla en otras lenguas (2, 1-13).

Esta constatación es importante para romper el imaginario impuesto al texlo desde fuera, como si el grupo de los once apóstoles fuera al que se le aparece Jesús resucitado, el grupo que es enviado y el que recibe el Espíritu en pentecostés. Este imaginario dominante es ajeno al texto y excluye a las muje- 
res. El texto de los Hechos, por el contrario, las incluye desde el primer momento en el relato. Ya hemos examinado Hechos 1, 1-5, texto restrictivo, en el que sólo los apóstoles reciben las últimas instrucciones de Jesús resucitado y a quienes se promete el bautismo en el Espíritu Santo. Pero como vimos, Hechos I, 1-5 es un agregado posterior, cuando la obra lucana fue dividida en dos. El agregado, pues, muestra un desarrollo teológico posterior, que es restrictivo con respecto al texto global original de Lucas 24 y Hechos I, 6ss.

Analicemos ahora Hechos 1, 6-I1, en el que se narran dos escenas distintas: el envio que hace Jesús resucitado a todos los que estaban reunidos (vv. 6-8) y su ascensión a los cielos (vv. 9-11). Buscamos claves de interpretación de estos dos eventos, cuya importancia es transcendental para la comprensión de todo el libro de los Hechos.

En Hechos 1, 6, los que están reunidos preguntan: "¿es en este momento que vas a restaurar el reino a Israel?". En Lucas 24, 21, los dos discípulos de Emaús habían dicho igualmente: "nosotros esperábamos que serfa él el que iba a liberar a Israel".

Si Hechos 1, 6 continúa el relato de Lucas 24, 1-49 y es en el contexto de ese relato que surge la pregunta, entonces es también todo el grupo reunido el que pregunta a Jesús. Es, por lo tanto, una pregunta de toda la comunidad. Y no se trata de un mal entendido, pues entre los que preguntan en Hechos 1, 6 están los dos discípulos de Emaús, que ya estarían claros con la larga explicación que Jesús les hizo de las Escrituras. Además, a todos los reunidos Jesús les había ya abierto la inteligencia para comprender las Escrituras (Lc 24, 45).

¿Cómo se explica que el grupo todavía mantenga la pregunta por la restauración del reino de Israel? En realidad, nos encontramos ante dos estrategias. En el evangelio de Lucas, Jesús busca realmente la restauración de Israel, aunque no identilica esta restauración con el proyecto teocrático de la restauración del poder político de Israel (proyecto mesiánico dominante), ni con la restauración del templo (proyeclo sacerdotal), sino con la restauración de la vida del pueblo, sobre todo de los pobres. Esa estralegia de Jesús culmina, realmente, con su muerte y resurtección, al linal del evangelio. Por lo tanto, es correcto que los discípulos pregunten por el restablecimiento ahora del reino de Israel. Lo que los discípulos no entienden es que la realización de esa restauración del pueblo se realiza por la muerte y resurrección de Jesús, lo que signilica tres cosas: no preocuparse por el tiempo y el momento de la restauración, no es el mismo Jesús que había convivido con ellos cl que ahora realiza directamente el proyecto, sino la fuerza del Espíritu Santo, y no se trata ya solamente de la restauración del pueblo de Israel, sino de ser testigos en Jerusalćn, Judea, Samaría y hasta el fin de la tierra.

Jesús propone ahora a sus discípulos y discípulas una estrategia nueva, que se realiza por la fuerza del Espíritu y del testimonio, y que tiene como itinerario estratégico Jerusalén (las autoridades de Israel), Judea (todo el pueblo), Samaría 
y toda la tierra. El proyecto de Jesús en el evangelio ha sido transformado ahora, por su muerte y resurrección, en un proyecto del Espíritu, que aclúa por los misioneros-testigos desde Jerusalén hasta los límites de toda la tierra (o como se dice en Lc 24, 48: "a todas las naciones, empezando desde Jerusalén"). La culminación del proyecto de Jesús en el evangelio (Lc 24) es ahora el comienzo de un proyecto del Espíritu y de los testigos de Jesús, que ahora tiene una dimensión universal (Hech 1, 8). La estrategia de Jesús según Hechos 1, 8 no contradice su estrategia desarrollada a lo largo del evangelio de Lucas. Hay continuidad al interior de una misma historia, que tiene, sin embargo, dos elapas distintas, cuyo eje de separación es la muerte y resurrección de Jesús. Jesús resucitado da una dimensión universal a su mismo proyecto del reino de Dios predicado en el evangelio.

La ascensión (Hech 1, 9-11) es el otro evento de esta sección inaugural (1, 6-11) y es uno de los hechos más difíciles de interpretar en la tradición de Jesús. Es importante recalcar que el relato de la ascensión en Hechos 1, 9-11 era el relato único, cuando el evangelio y los Hechos configuraban una sola obra. Las otras dos referencias a la ascensión, en Lucas $24,50-53$ y en Hechos 1, 1-2, fueron agregadas posteriormente, cuando las dos obras se separaron. Además, Lucas es el único autor del Nuevo Testamento que habla de la exaltación de Jesús, entendida como ascensión y como hecho separado de su resurrección. La tradición originaria común presenta, más bien, la resurrección de Jesús en sí misma como exaltación o glorificación (cfr., por ejemplo, Rom 1, 4: "constituido Hijo de Dios con poder, según el Espíritu de santidad, por su resurrección de entre los muertos"; cfr., además, Fil 2, 6-11 y toda la tradición del cuarto evangelio). Lucas separa ambos evenlos (resurrección y exaltación), lo cual implica una doble historización. Por un lado, presenta a Jesús resucitado como un Jesús histórico, vivo y presente en nuestra historia; y por eso, Lucas insiste en la corporeidad de Jesús resucitado: no es un fantasma, tiene carne y huesos, pueden tocarlo, come con ellos. Y por otro lado, presenta su exaltación también como un hecho histórico, lo cual es más difícil de entender.

La opinión teológica corriente y el imaginario colectivo de la Iglesia tienen una visión des-historizada de la ascensión-exaltación de Jesús y una correspondiente visión des-escalologizada de la Iglesia. Nomalmente, la ascensión de Jesús se interpreta como su partida de este mundo: Jesús se habría ido a otro mundo, para regresar al final de los tiempos. La desaparición de Jesús de este mundo sería necesaria para la constitución de la Iglesia en este mundo, una Iglesia conducida ciertamente por el Espíritu, pero sin ninguna dimensión escatológica.

Hay aquí una serie de malos entendidos y de falsas interpretaciones. En primer lugar, la de entender la ascensión de Jesús como su desaparecimiento de este mundo. En loda la tradición apostólica, en efecto, se insiste en que Jesús resucitado y exaltado nunca se va (recuérdense especialmente las últimas palabras de Jesús en MI 28, 19: "he aquí que yo estoy con ustedes todos los días 
hasta el fin de este mundo"). Por eso es impropio hablar de la segunda venida de Jesús como del retorno de alguien que se hubiera ido. Según la tradición, Jesús no vuelve, simplemente porque nunca se ha ido. Lo que esperamos no es el rctorno de un Jesús ausente, sino la manifestación gloriosa de un Jesús que siempre ha estado en medio de nosotros. La parusía no es un retorno, sino una manifestación gloriosa. Según esto, el sentido de Hechos 1, Il lo podríamos expresar más o menos así: este Jesús ha sido exaltado con poder y también con poder se va a manifestar entre nosotros. Por eso, los discípulos no deben seguir mirando al cielo, sino que tienen que mirar a la tierra, donde se da y se seguirá dando la manifestación gloriosa de Cristo resucitado.

En segundo lugar, una falsa interpretación de la ascensión lleva a una des-escatologización de la Iglesia, es decir, la Iglesia pierde su dimensión escatológica, tal como lo pensó y recalcó la teología liberal. Esta teología ha presentado el surgimiento de la Iglesia, especialmente en los Hechos, como una necesidad para suplir la no-realización de la segunda venida inminente de Jesús. Según esta leoría, la primera generación cristiana esperaba la pronta venida de Jesús y para responder a la frustración de su no venida, la segunda generación cristiana (la del perfdo sub-apostólico, posterior al 70), y en ella especialmente Lucas, planteó la necesidad de la construcción de la Iglesia para la época entre la resurrección de Jesús y su venida al final de los tiempos. En esta teoría, lo escatológico se reduce a la segunda venida de Cristo, al final de los tiempos.

En mi opinión, esta visión es falsa, des-historiza la resurrección y ascensión de Jesús, y des-escatologiza a la Iglesia. En la visión de Lucas, Jesús resucitado está presente hisıóricamente en el mundo y en la comunidad cristiana, pero, a la vez, lo está como Cristo exaltado y glorificado. La presencia de Jesús es histórica, aunque no sea una presencia visible y empírica, sino una presencia trascendente, pero que se da siempre en la historia. La experiencia escatológica fundamental de la Iglesia es esta experiencia histórica de la resurrección de Jesús en el mundo y en la comunidad. La Iglesia en los Hechos es, entonces, una lglesia pneumálica y escatológica, no porque espera que acaezca pronto la segunda venida de Jesús, sino porque vive históricamente la experiencia de Cristo resucitado y glorificado, en el mundo y en la comunidad. Esta dimensión cscatológica de la Iglesia se expresa en los Hechos cuando Jesús resucitado se sigue aparcciendo en los momentos difíciles de la Iglesia (a Esteban, a Pedro, a Pablo), pero sobre todo es vivida en la experiencia del Espíritu Santo en la Iglesia. La eclesiología de Lucas es histórica. justamente porque es definitivamente una eclesiología escatológica y pneumática4.

4. Para profundizar en este tema, véase R. Aguirtc y A. Rodríguez, op. cil., pp. 342345. donde se presenta la reacción aclual a las opiniones de Vielhauer, Conzelmann y Haenchen. 


\section{La Iglesia de Jerusalén: 1, 12 - 5, 42}

\section{Algunas claves de interpretación}

\section{Sumario: 1, 12-14: la comunidad antes de pentecostés}

El texto comienza ubicando el lugar donde está el grupo de los "galileos": "volvieron a Jerusalén desde el monte llanado de los olivos... y cuando Ilegaron subieron a la estancia superior donde vivían" (vv. 12-13a). Es la primera noticia que tenemos en los Hechos de que el grupo estaba fuera de Jerusalén y que la ascensión tuvo lugar fuera de la ciudad, en el monte de los olivos. El único dato anterior a Hechos lo tenemos al final del evangelio de Lucas (24, 50-53), agregado posterior, cuando el evangelio se separó de los Hechos. Allí se dice que la ascensión ocurrió cerca de Betania, pueblo ubicado un poco más de tres kilómetros al este de Jerusalén, mientras que el monte de los olivos está a menos de un kilómetro. En Hechos 1, 12 y en Lucas 24, 52 se dice que volvieron a Jerusalén y se usa el término sacro lerousalem y no la designación neutra de lerosolima. El nombre sacro se refiere a Jerusalén como ciudad santa, lugar del templo y de la institucionalidad judía, mientras que la designación neutra lerosólima es puramente geográfica (Rius-Camps). Según Lucas 24, 50, Jesús "los saco" fuera de lerousalem (nombre sacro), dando a entender que los liberó de la institucionalidad judia, y sin embargo, ahora vuelven a ella. Por eso, Hechos 1, 12 dice que estaban lejos de un camino sabático, es decir, que el regreso no supuso romper la ley del sábado. El grupo sigue, pues, dentro todavía de la institucionalidad judía. De hecho, según Lucas 24, 53, el grupo regresa a Jcrusalén; mientras que en Hechos 1,13 sólo se menciona "la cstancia superior, donde vivían". Se trata de una casa $(2,2)$, posiblemente en las cercanías del tcinplo. Es ahí donde tienen que dar testimonio ("serán mis testigos en lerousalem", I, 8).

¿Quiénes están reunidos? Ya hemos dicho que en Lucas 24 y en Hechos I-2 se trata de un grupo grande: "los once y todos los demás" (Lc 24, 9.33), lo que incluye al grupo de las mujeres, los dos discípulos de Emaús y a otros, "unos 120 " ( 1,15$)$, que son los inismos reunidos en I, 6. Ilamados "galileos" en I, II. Ahora se especifica que el grupo grande de 120 galileos estaba compuesto por tres grupos: los once apóstoles (citados por sus nombres), algunas mujeres, María, la madre de Jesús, y sus hermanos. Estos tres grupos (los apóstoles, las mujeres y los hermanos de Jesús) "perseveraban en la oración con un mismo espíritu".

Los apóstoles y las mujeres, incluida la madre de Jesús, son dos grupos ya conocidos y delinidos, de ahí que la sorpresa es la presencia de los hermanos de Jesús. Estos aparecen en Lucas 8, 19-20, donde conscientemente se corrige el texto de Marcos, en el cual sc hace una presentación muy negativa de estos hemnanos como no-discípulos, como los que están fuera, los que lo consideran loco (Mc 3, 20-21.31-35): y en la misma línea cstá Juan 7, 1-10 ("ni siquiera 
sus hermanos creían en él"). En Hechos ya no aparecen eslos hernanos de Jesús, mencionados como grupo, pero sí aparece uno de ellos, Santiago, quien tendrá un rol importante en la Jglesia de Jerusalén después de Pedro (cfr. Hech 12, 17; 15, 13; 21, 18). Según Marcos 6, 3, los herımanos de Jesús se Ilamaban Santiago (que aparece en Hechos), José, Judas y Simón, y dos hermanas, de las cuales no se da el nombre. Históricamente cs posible que estos tres grupos, que ahora cstán reunidos, tuvieran teologías y estratcgias diferentes y quizás opuestas, pero por el momento Lucas insisle en que "perseverahan en la oración con un mismo espíritu", término redaccional, que hace sospechar una realidad histórica dilierente.

\section{Constitución de los doce apóstoles: 1, 15-26}

El relato comienza con una composición de lugar: ticmpo y actores (v. 15). Tiempo: "uno de aquellos días", es decir, después de la ascensión-exaltación de Jesús y antes de la venida del Espíritu, en pentccostés. Pedro clige justamente ese tiempo, cuando hay una especie de vacío de poder divino, para la elección del sucesor de Judas. Pedro se levanta en medio de una asamblea constituida por 120 micmbros, reunida allí "con un mismo propósito" (epi to autó). El número legal para elcgir un consejo o sancdrín que representara a Israel era jusiamente 1205 .

El discurso de Pedro liene dos partes: una expositiva (vv. 16-20) y otra parenélica (vv. 21-22). Todos los discursos de los Hechos fueron normalmente compuestos por el mismo Lucas, pero éste usa tradiciones que son históricas o hechos históricos con los cuales reconstruye el discurso tal como más o menos debió haber sido. El argumento que da Pedro en su discurso es el cumplimiento de dos citas bíblicas, que Lucas reconstruye para interpretar la realidad de la elección de un sucesor de Judas. La primera cita esı́́ Iomada del Salmo 69, 26, donde una maldición contra los enemigos del justo pide que la habitación de cllos quede desierla y que no haya quien habite en sus tiendas. Lucas cambia el plural en singular, para referirlo a Judas. El sentido del texto, sin embargo, exige que el puesto de Judas, abandonado por Iraición (no por muerte), quede desierto. lo que estaría en contra de la elección de un sustituto, y por eso Lucas añade la cita de otro texto, el Salmo 109,8, donde la maldición contra el implo consiste en que sus dlas sean pocos y otro ocupe su cargo (cargo traduce el gricgo episcopé, quizás aludiendo a la realidad posterior de los epíscopos). Los textos que cita Pedro (Lucas) no hacen alusión a la traición y a la muerte de Judas, sino a la necesidad de elegir a alguien que lo sustituya. $Y$ la información que

5. Cfr., J. Rius Camps, De Jerusalén a Antioquia. Génesis de la Iglesia cristiana, Córdoba, 1989, p. 49. 
Iransmite Pedro sobre la muerte de Judas dificre de la de Mateo (27, 3-10). Aquí Judas muere cayendo de cabeza (la caída del impio: Sab 4, 19: "el Señor los quebrará lanzándolos de cabeza"). Judas compra un campo con el precio de su iniquidad y es ahi donde revienta, cuando cae de cabeza, y por eso se llama "campo de sangre".

En la segunda parte del discurso. Pedro pone las condiciones que debe tener el candidato para suslituir a Judas (vv. 21-22). Pedro llama al puesto que debe ser ocupado "porción en este ministerio" (kleros tes diakonías tautes, v. 17) o "lugar en este ministerio y apostolado" (topos tes diakonias rautes kai apostolés, v. 25). El ser apostol, es por lo tanto, tomar parte en un servicio (una diakonía), un ministerio, un apostolado. Las condiciones que pone Pedro y que definen quién es el verdadero apóstol, son dos. En primer lugar, debe ser un varón. Pedro dice literalmente: "uno de los que anduvieron con nosolros varones" (usa aner y no anthropos que podría ser inclusivo). Pedro excluye asi a las mujeres que estaban presentes en la asamblea. En segundo lugar, debe ser uno de los discípulos que estuvieron con Jesús, desde el bautismo de Juan hasta el día de la ascensión. Con esto Pedro también excluye, hacia atrós, a los hermanos de Jesús (y entre ellos a Santiago), que también estaban presentes en la asamblea, pues éstos no fueron discípulos de la primera hora, sino que, todo lo contrario, no creyeron en él. Pero también excluye, hacia adelante, a todos los que después tendrán una experiencia de Jesús resucitado (como Esteban, Pablo y lantos otros), que no estuvieron con Jesús desde el principio.

Sólo el que cumpla estas dos condiciones puede ser agregado al número de los doce apóstoles y ser constituido en "testigo con nosotros de su resurrección". La asamblea presentó a dos que cumplían con las condiciones estipuladas: José, llamado Barsabás, por sobrenombre Justo, y Malías. El modo de elección fue la oración en común y, mecánicamente, "echando suertes", la cual recayó sobre Matías6.

Si hacemos ahora una lectura crítica de Hechos 1, 15-26 varias cosas llaman la atención. En primer lugar, el momento que Pedro eligió para completar el número de los doce apóstoles ¿Por qué no esperaron a la venida del Espíritu? Además, hay que recordar que la orden de Jesús antes de su ascensión fue "permanezcan quietos (literalmente: sentados) hasta que sean revestidos del poder de to alto" (Lc 24, 49; cfr., Hech 1,4). Pedro actúa, pues, en contra de la agenda marcada por Jesús de no hacer otra cosa que esperar y aguardar. Ade-

6. El texto no excluye una elección formal. Literalmente se dice que "dieron suertes a ellos (edokan klerous ausois), es decir, "entregaron votos a ellos". La expresión del Antiguo Testamento para una elección por suerles es "echar suertes" (ballein klerous). Si la elección de Matías fue por volación de la asamblea, eso significaría que era el candidato de la mayorfa. En este sentido interpreta Rius-Camps la elección. 
más, ¡por qué no cligió dircclamente Jesús al nuevo apóstol antes de su ascensión? ¿Por qué el apuro de Pedro de elegir al sustituto de Judas ya antes de pentecostés?

Los autores normalmente explican esta elección argumentando que son doce los que representan legítimamente a Israel y que ellos son los que, como nuevo Israel, recibirán el Espíritu Santo. Por eso era necesario completar el grupo de doce ya antes de pentecostés. Pero, si esto es así, ¿por qué no lo hizo Jesús dircctamente o por lo menos ordenó dicha elección? Como ya dijimos, y volveremos sobre el punto, los que reciben el Espíritu Santo no son sólo los doce, sino lodos los reunidos en la casa (los 120 hermanos: Marla, las mujeres, los hermanos de Jesús y otros). Otros autores, sin embargo, como Rius-Camps, piensan que la elección fue para reconstruir la autoridad de los apóstoles, dañada seriamentc por la traición de uno de ellos (Judas). Esa reconstrucción de los doce apóstoles se haría contra las pretensiones de poder del grupo de los hermanos de Jesús, a lo que agregaría que también se buscaba excluir a las mujeres, el otro grupo allí presente.

También hay que someter a crítica la definición excluyente que se hace del apóstol en 1, 21-22. Especialmente llamativa es la exclusión de las discípulas de Jesús, que estuvieron con él desde Galilea y fueron las primeras testigos de la resurrección, así como de los discípulos futuros y también testigos de la resurrección, como Paulo de Tarso. Es sabido que Lucas no considera a Pablo como apóstol. lo que el mismo Pablo defiende con insistencia y fuerza en sus cartas. Además, Pablo incluye explícitamente a una mujer en el rango de apóstol: "Saluden a Andrónico y Junia (nombre de mujer)... ilustres entre los apóstoles, que Ilegaron a Cristo antes que yo" (Rom 16,7).

Esta definición restrictiva de apóstol hecha por Pedro en su discurso (y quizás por Lucas) mira fundamentalmente al pasado y restringe el apostolado a un tiempo determinado: la vida de Jesús y el primer momento de testimonio en Jerusalén. Los doce apóstoles son los que aseguran la continuidad con Israel y con el proyecto de Jesús de restaurar Israel, así como la continuidad con la primera comunidad de Jerusalén. Como veremos, en los Hechos, los doce cumplen un rol fundamentalmente en Jerusalén y sólo en la comunidad de la Jerusalén de los primeros tiempos.

Por último, llama también la atención la forma como fue elegido Matías: no hay un discernimiento de la asamblea, como ocurrirá en Hechos 6, 1-6 (la elección de los siete diáconos) o en 15, 22 (la asamblea de Jerusalén). Tampoco se trata de una elección guiada directamente por el Espíritu, como en 13, 1-3 (envío de Bernabé y Saulo a misionar). La elección se lleva a cabo simplemente echando a suertes, si bien este método respondía a una forma arcaica de discernimiento de la voluntad de Dios (cfr. Ex 33, 7; ISam 14, 41; Lc 1, 9). 


\section{Pentecostés: 2, 1-41}

La irrupción del Espíritu en pentecostés es la consecuencia directa, histórica y visible en la tierra de la resurrección y de la exaltación de Jesús: "exaltado por la diestra de Dios, ha recibido del Padre el Espíritu Santo prometido y ha derramado lo que ustedes ven y oyen" (v. 33). Es el Espíritu el que constituye realmente el movimiento de Jesús: su primera comunidad en Jerusalén y la misión a todos los pueblos. Lo que Lucas ha narrado anteriormente en 1, 12-26 está más bien orientado al pasado: regreso a Jerusalén y al templo, y restauración de Israel (constitución de los doce apóstoles). Ahora, Lucas retoma el inicio de su relato en 1, 6-11 y proyecta el movimiento de Jesús hacia el futuro y hacia todos los pueblos de la tierra.

Una mirada crítica al relato descubre la aclividad redaccional y creadora de Lucas. Es Lucas el que ha construido el paradigma de pentecostés, pero lo hace a partir de muchos hechos y tradiciones históricas. Todo lo que narra es histórico, pero el autor construye un relato único a partir de hechos que, posiblemente, sucedieron varias veces, en diferentes lugares, liempos y circunstancias. También el discurso de Pedro lue posiblemente compuesto por Lucas, pero lo hace a partir de tradiciones escritas u orales. El discurso que compone Lucas corresponde históricamente a lo que en ese entonces pensaba y decía la primera comunidad apostólica en Jerusalén. Lucas recoge, pues, los hechos históricos y las tradiciones que transmiten estos hechos, pero también le interesa el efecto creativo de estos hechos y tradiciones en la historia de la Iglesia de su tiempo y de todos los tiempos.

En el relato de lo acontecido alredcdor de pentecostés, muchos autores distinguen dos fuentes. En forma más sencilla podemos distinguir dos relatos: uno más primitivo y tradicional, que se refleja en los vv. $1-4$ y 12-13, y otro más evolucionado y redaccional, en los vv. 5-11. El relato antiguo tiene un carácter carismático y apocalíptico: hay viento impetuoso y lenguas como de fuego; los presentes hablan en lenguas (vv. 1-4) y por eso aparecen ante los demás como borrachos; los hechos suceden en una casa (v. 2). El segundo relato es profético y misionero: ya no se trata de hablar en lenguas (glosolalia), sino de un don prolético: los presentes hablan en galileo (arameo) y cada cual los entiende en su propia lengua naliva. El milagro no consiste en el hablar (como en la glosolalia), sino en el escuchar (sobre lo que se insiste en tres lugares: vv. 6, 8 y II). Los que están reunidos para escuchar son un grupo grande. Si el evento primitivo se da en una casa; ahora, en el segunto relato tenemos la impresión de estar más bien en el templo. Posiblemente, Lucas unió aqul, en un solo relato, dos tradiciones históricas, cada cual con un sentido diferente.

En 2, 1 se dice que "estaban rodos reunidos". No se trata sólo de los doce apóstoles, sino de la asamblea de los 120 (v. 1, 15), entre los cuales está María, la madre de Jesús, el grupo de las mujeres y el grupo de los hermanos de Jesús, 
y entre ellos, con certeza, también Santiago, el hermano del Señor (v. 1, 14). El don del Espíritu se da a esta primera comunidad, si hien es Pedro, junto con los once, el que va a pronunciar el discurso ( $v$ v. 14 y ss.). Se dice también que están reunidos "con un inismo propósito" (epi to autó, lo que a veces se suele traducir "en un misino lugar"). Este mismo propósito o estrategia es posiblemente la restauración del reino de Israel (esa fue la pregunta en el v. 1,6 y el sentido de la elección de Matías en el v. 1, 15-26). La irrupción del Espíritu viene a romper este propósito de restauración, que mira más al pasado que al futuro. El Espíritu viene de repente, con ruido como de viento impetuoso y como lenguas de fuego: todos estos símbolos muestran la "violencia" necesaria del Espíritu para transformar al grupo presente y reorientar la primera comunidad, desde una posición resłauracionista hacia una posición profética y misionera. Estc es el bautismo del Espíritu Santo, anunciado en el v. 1, 5. El bautismo de Juan Bautisla era de agua, un símbolo judio de conversión personal; ahora se Irata del bautismo del Espíritu, el símbolo caractcrístico del movimiento profético de Jesús, no ya de conversión personal, sino de transformación de la comunidad de los discípulos en auléntica comunidad profética, para dar testimonio hasta los confines de la tierra.

Los que se reúnen, atraídos por los sucesos de pentecostés, son "hombres piadosos, que habitaban en Jerusalén, venidos de todas las naciones que hay bajo el cielo". Tenemos aquí una ficción literaria de Lucas, pues es impensable que estuviese reunida en Jerusalén gente piadosa de todas las naciones del mundo. El hecho es tan extraordinario, que manuscritos posteriores (tradición occidental) agregan la palabra "judíos": los reunidos serían "judíos de todas las naciones que habitan en Jerusalén". Lucas tiene una clara intención teológica: reúne simbólicamente en Jerusalén a gente piadosa de todas las naciones del mundo que, a partir de pentecostés, va a recibir el testimonio profético de la primera comunidad apostólica. El Espíritu es derrarnado en función de todos los pueblos y culturas del mundo. Para Lucas, cso ya ocurre en el hecho fundante de pentecostés.

En los vv. 9-11 tenemos la lista de la naciones. Lucas enumera doce pueblos y tres regiones. El primer grupo lo constituyen los nativos partos, medos y elamitas7. El segundo grupo son los habitantes (hoi katoikountes) de Judea, Capadocia, Ponto, Frigia, Panfilia y Egipto, y aquí también sc enumeran tres regiones (que aparecen con artículo): la Mesopotania, cl Asia y la Libia, que confina con Cirene. El (ercer grupo son los forasteros (hoi epidemountes): romanos (habitantes de Roma, sean éstos judíos o prosélitos), cretenses y árabes.

7. La última lrase del v. 8. "en nuesıra propia lengua en la cual nacimos" (en he egennethemen), se refierc especialmente a los partos, medos y elamitas. Por eso, los llannados "nativos" son pueblos que hablan sus Ienguas nativas (cfr. Rius-Camps, op. cit.). 
¿Cuál es la lógica de esta enumeración? En primer lugar, Lucas distingue nativos, habitantes y forasteros. Los nativos son pueblos al oriente, civilizaciones del pasado. Los habitantes están repartidos en tres regiones: la Mesopotamia (al este), el Asia (al norte) y la Libia (al sur); y en seis pueblos: Judea (al centro), Capadocia, Ponto, Frigia y Panfilia (al norte) y Egipto (al sur). Por último, los forastcros o visitantes: romanos (código étnico que no hace referencia a las fuerzas del imperio romano), que vienen de visita a Jerusalén, y entre los que se distinguen romanos judíos y romanos prosélitos (no judios que se han convertido y han aceptado la circuncisión); cretenses, pueblo marítimo en expansión hacia occidente, y los árabes, que sería una designación global para referirse a los pueblos del desierto, en expansión hacia oriente.

La lógica geográfica es la que domina al grupo de los habitantes (oriente, norte y sur, con Judea en el centro). Los visitantes (romanos, cretense y árabes) no siguen una lógica geográfica, sino más bien de visitantes esporádicos (grupos amplios y ambiguos), que regresan a su patria. En síntesis, los representantes de los pueblos vienen de todas las regiones de la tierra, de las culturas antiguas de oriente, de los pucblos establecidos en torno a Juden (oriente, norte y sur) y de las poblaciones que se desplazan hacia oriente y occidente, cuyo centro es Roma. Lucas combina así crilerios culturales, geográlicos y sociales, y construye históricamente el paradigma misionero del Espíritu. Lo curioso es que no se mencionan Siria, Macedonia y Grecia, que es el territorio de las iglesias paulinas. Quizás estos pucblos no aparecen porque es ahí donde Lucas escribe su obra y son ya en su tiempo iglesias independientes de Jerusalén.

Lucas insiste tres veces ( $v v .6,8$ y 11 ) en que los presentes, que vienen de todos los pueblos, entienden el discurso de Pedro, cada uno en su propia lengua. Pedro y los once son galileos (v. 7) y hablan, por lo tanto, en arameo, que era una lengua bastante conocida en Siria y en oriente. El milagro de pentecostés es que cada uno entiende en su propia lengua nativa. No se trata de la glosolalia, pues éste es un milagro en el hablar, y aquí el milagro se sitúa en el escuchar y entender. Cada puebio escucha el evangelio en su propia lengua y-podríamos agregar- cn su propia cultura. Por eso, hoy en día, pentecostés es considerado como la fiesta cristiana de la inculturación del evangelio.

Muchos comentaristas oponen pentecostés a la confusión de lenguas en Babel (Gen 11, 1-9). Por lo que toca a Babel, la unidad original de lenguas fue lo que permitió la construcción de la ciudad con una torre militar, que es el proyecto de dominación (Gen 11, 2-4), mientras que la recuperación de las lenguas nativas hizo posible detener la construcción de la ciudad, lo que se identifica con el proyecto liberador de Yahvéh (Gen 11, 5-8)8. Una lectura del relato del

8. Cfr. Milion Schwantes. "La ciudad y la tierra", en Las iglesias en la práctica de la justicia. San José. 1981. pp. B1-92. 
Génesis desde la perspectiva dominante y colonial siempre vio la pluralidad de lenguas y culturas como una maldición, y así, en pentecostés se habría recuperado la unidad perdida en Babel (así lo interpreta, por ejemplo, la nota de la Biblia de Jerusalén a Hech 2,6). Sin embargo, desde la perspectiva liberadora de la inculturación del evangelio, la diversidad de lenguas fue el hecho liberador que permitió la huída de los trabajadores y la paralización de la construcción de la ciudad. En pentecostés cada pueblo conserva su lengua y su cultura, y lo nuevo es la unidad en la comprensión del evangelio, manteniendo la diversidad de lenguas y culturas. La unicidad de lenguas no es el proyecto original de Dios, ni tampoco su recuperación en pentecostés, sino una forma de dominación cultural. El proyecto original de Dios, recuperado en pentecostés, es más bien una humanidad plurilingüe y multicultural.

El discurso de Pedro (vv. 14-36) liene dos partes: vv. 14-21 y 22-36. En la primera, parte Pedro se dirige a "los judios y habitantes todos de Jerusalén", donde se incluye implícitamente sobre todo a los visitantes piadosos de todos los pueblos presentes en Jerusalén. En esta parte del discurso, Pedro se refiere directamente a los hechos extraordinarios de pentecostés (narrados en los vv. I-13), especialmente al relato antiguo (vv. 1-4), donde se da el fenómeno de la glosolalia, que causa la impresión de que todos los que reciben el Espíritu están borrachos (vv.12-13). En la segunda parte de su discurso (vv. 22-36), Pedro se dirige exclusivamente a los "israelitas" y se refiere explícitamente a los judíos de Galilea y Judea, que vivieron de cerca y en vivo todos los hechos de Jesús hasta su muerte. Ahora, el hecho de pentecostés queda integrado en un discurso global eminentemente cristológico.

Pedro utiliza tres textos bíblicos: Joel 3, 1-5, el Salmo 16, 8-11 y el Salmo 1]0,1. El discurso ha sido compuesto por Lucas pero, ciertamente, recoge la tradición histórica de la primera generación cristiana, especialmente la forma cómo se interpretaba la Biblia hebrea. En electo, ninguno de los textos bíblicos citados se refiere a lo que la comunidad está viviendo: la resurrección y la exaltación de Jesús y los hechos de pentecostés. Sin embargo, la comunidad interpreta los hechos que vive a la luz de las Escrituras, con lo cual tanto la rcalidad que vive, como los textos que cita, adquieren un nuevo sentido. Los hechos interpretan las Escrituras y éstas explican los hechos. En csta hermenéutica apostólica, los textos son leídos, interpretados y a veces incluso re-construidos con bastante libertad.

En la primera parte de su discurso, Pedro cita a Joel 3, 1-5, pero cambia el comienzo del texto: en vez de "sucederá después de esto", dice -como palabra de Joel- "sucederá en los últimos días". Es un texto claramente apocalíplico: "los últimos días" (v. 17) es el liempo después de la resurtección de Jesús. "El día grande del Señor" (v. 20) no es, en primer lugar, el día del juicio final y del fín del mundo, sino igualmente el día inaugurado por la resurrección de Jesús, 
que se prolonga por su exaltación y la efusión del Espíritu a la largo de la historia. Las transformaciones cósmicas de los vv. 19-20: prodigios en el cielo y señales en la tierra, sol en tinieblas y luna en sangre, es el lenguaje típico de la apocalíptica cristiana para interpretar las tranformaciones históricas del tiempo presente (en el mismo sentido, cfr. Apoc 6, 12-18). Los signos cósmicos son utilizados teológicamente para interpretar la importancia Iranscendental de los hechos que suceden en el tiempo histórico presente. Pentecostés es la manifestación fundamental de este tiempo escatológico y apocalíptico, inaugurado por la resurrección de Jesús9. Lo fundamental de este tiempo apocalíplico del Espíritu es que éste es derramado "sobre toda carne": hijos e hijas, jóvenes y ancianos, esclavos y esclavas. En este tiempo del Espíritu, todos y todas son profelas. El versículo final de la profecía de Joel subraya este universalismo: "todo el que invoque el nombre del Señor se salvará". En el texto griego del Antiguo Testamento, el título "Señor" traduce el nombre de Dios, que la comunidad cristiana primitiva aplicó directamente a Jesús. Este versículo le sirve a Lucas como transición para la segunda parte del discurso.

Esta segunda parte es cristológica (vv. 22-36) y se dirige explícitamente a los "israelitas" (v. 22) y a "toda la casa de Israel" (v. 36). La estructura y el contenido es el siguiente:

(1) v. 22: vida pública de Jesús antes de su muerte. Jesús fue hombre acreditado por Dios con milagros, prodigios y señales.

(2) v. 23: inuerte de Jesús. Pedro acusa directamente al pueblo judío: "Ustedes lo mataron clavándolo en la cruz por mano de los impíos". La responsabilidad del pueblo en la muerte de Jesús no significa un fracaso de Dios, pues Dios lo sabía y asf lo tenía determinado. Aquí, Pedro acusa al pueblo, pero claramente la acusación va dirigida contra los jefes, ancianos, escribas y sumos sacerdotes (cfr. $4,5.10$ y 5,28).

(3) vv. 24-32: resurrección de Jesús. A este Jesús Dios le resucitó (irase que se repite al comienzo y al final de este parrafo). Pedro utiliza el Salmo 16, 8-11. Este texto brblico no habla del mesías ni de su resurrección, sino del hombre perseguido, que pone toda su confianza en Dios. Pedro, sin embargo, lo aplica a Jesús, con lo cual reconstruye el sentido del salmo y simultáneamente interpreta la muerte y la resurreción de Jesús a la luz de las Escrituras. Como ya dijimos, la comunidad interpreta las Escrituras, cuando, a la luz de ellas, comprende la realidad actual. Pedro da testimonio de la resurrección de Jesús, es decir, el anuncio va acompañado del testimonio: Pedro compromete públicamente su vida en lo que afirma solemnemente. No basta interpretar las Escrituras, es, además, necesario el testimonio personal de los discípulos.

9. Este es el inensaje central del libro del Apocalipsis. Véase, P. Richard, Apocalipsis. Reconsiruidos en la esperanza, San José, 1994. 
(4) vv. 33-35: Jesús es exaltado, recibe el Espíritu y lo derrama a lodos, que es lo que todos están viendo y oyendo. Nueva interpretación biblica, esta vez del Salmo 110,1 . Pedro termina refiriéndose a los hechos de pentecostés, que es lo que motiva el discurso.

(5) v. 36: conclusión: "Sepa con certeza loda la casa de Isracl que Dios ha constituido Señor y Mesias a este Jesús a quien ustedes han crucificado". Jesús ya era Señor y Mesías, pero ahora ha sido constituido en tal con poder, a partir de su resurrección y exaltación, ante todo el pueblo de lsrael. La efusión del Espíritu es la prueba sensible de ello y su raíz es Jesús glorificado.

La multitud que escucha a Pedro interumpe el discurso e interviene con una pregunta clave: "¿Qué hemos de hacer, hermanos?". Pedro ha dado testimonio con plena autoridad, como el nuevo jefe de Israel; él es ahora el que debe orientar al pueblo de Israel. Su respuesta responde a un esquema tradicional: conversión y bautismo en el nombre de Jesucristo para el perdón de los pecados y así poder recibir el don del Espíritu Santo.

El bautismo fue una práctica común en los profelas y los mesías populares, como en el caso de Juan Bautista, y aquí no se trala todavía del bautismo específicamente cristiano. Posiblemente, Lucas refleja una costumbre de la Iglesia de su tiempo, cuando el baulismo significaba explícilamente pcrtenencia a ésta, como identidad diferente de la sinogoga y de toda institución judía, pero no sabemos cuándo se impuso la tradición del bautismo crisliano. En los profetas populares, el bautismo junto al río era un rilo alternativo al templo y marcaba un movimiento de ruplura con la institucionalidad sacerdotal de aquel. El bautismo cristiano debió nacer poco a poco dentro de esta tradición profética y mesiánica popular. El bautismo como rito implicaba arrepentimiento y perdón de los pecádos. Juan Bautista proclamaba "un bautismo de conversión para perdón de los pecados" (LC 3, 3). Lo nuevo ahora, después de la resurtección y exaltación de Jesús, es que los bautizados reciben el don del Espírilu Santo. Esle don es para lodos: para los judios y para los gentiles ("Ios que están lejos" v. 39, cilando a Is $57,19)$. Así lo recibirán los samaritanos $(8,15-17)$ y el centurión romano Cornelio $(10,44-48)$.

En el v. 40 tenemos un recurso literario, resumen o sumario, para dar a entender que Pedro no sólo pronunció el sernón que acabamos de analizar, sino que dijo muchas olras cosas. Lucas recuerda una sola frase de toda la instrucción adicional de Pedro: "Sálvense de esila generación perversa". La "generación perversa" puede ser aquella que en el desierto se rebeló conlra Dios (D1 32,5) o la que rechazó a Jesús $(\operatorname{Lc} 9,41)$. Ahora sería la que rechaza el lestimonio de Pedro. Por el contexto, se refiere a las autoridades de Israel. El pueblo de Israel, guiado ahora por los apóstoles, debe seguir a Jesús, recibir su Espíritu y salvarse de la generación perversa de los jefes, ancianos y sumos sacerdotes del templo. 
Sumario: 2, 42-47: la comunidad después de pentecostés (cfr. los sumarios $4,32-35$ y $5,12-16$ )

Tenemos aquí un recurso literario lípico de Lucas: el uso de sumarios. Estos son utilizados para generalizar hechos concrclos y representar una situación global y permanente. Lucas dispone de muy pocos hechos para reconstruir la vida de la comunidad de Jerusalén de los prinicros años: la elección de Matías, la curación de un tullido y noticias sobre Bernabé, Ananías y Safira. Para reconstruir la vida permanente y global de la comunidad debe usar olro género literario: no el relato de hechos particulares, sino un sumario de hechos repelidos y constilutivos. En la primera parte de los Hechos (capílulos 1 al 5) tenemos tres sumarios sobre la vida de las primeras comunidades: $2,42-47 ; 4,32-35$ y 5 , 12-16. De los olros dos sumarios, Hechos 1, 12-14 licne una función introducloria (la comunidad antes de pentecostés) y Jjechos 5, 42 es un sumario conclusivo (actividad de los apóstoles en el templo y por las casas).

Los tres sumarios sobre la vida de la comunidad tienen como lexto básico la frase de 2, $42-43$ (que algunos aulores piensian que proviene de una fuente antcrior a Lucas). Todo lo que se desarrolla en los tres sumarios es una ampliación de esta frase, y por eso veremos aqui los tres sumarios juntos (aunque hay que nolar la ubicación estratégica de ćslos en la estructura de llechos 1, 12 - 5, 42). En estos sumarios se relatan las actividades constitutivas de la comunidad después de pentecostés; no son hechos aislados, sino acciones permanentes y fundanles. Veamos cada una de ellas.

(1) Eran perseverantes en la enseñanza de los apósfoles $(2,42)$. La enseñanza, en griego didajé, de los apóstoles, debe referirse "a todo lo que Jesús hizo y enseñó desde el principio" $(1,1)$. Los apósiloles se definen como los hombres que anduvieron con el Señor Jesús mientras él convivió con ellos $(1,21)$ y como testigos de su resurrección. La comunidad está fundada sobre esta enseñanza, que es el lestimonio directo de los discipulos y de las discípulas de Jesús, Ilamada la tradición apostólica. Es la "memoria histórica" de Jesús de Nazareth. Esto es lo que funda y da identidad a la comunidad.

(2) Eran perseverantes en la comumión $(2,42)$. La comunión, en griego koinonía, es una manera de vivir en comumidad, que Lucas va a desarrollar en sus tres sumarios. En forma esquemálica podemos decir que liene dos dimensiones: una subjeliva y olra objeliva. La dimensión subjetiva se expresa con la fómmula: "ienían un solo corazón y alma" $(4,32)$, es decir, conslituían un solo cuerpo, con un solo corazón y alma. La dimensión objeliva es más compleja, y la podríamos resumir esquemáticamente en tres actividades: (a) lenían todo en común, pues vendían sus posesiones y sus bienes $(2,44-45)$; nadie llamaba suyos a sus bienes, pues todo era común entre ellos $(4,32)$; lodos los que tenían campos o casas los vendían y lo ponían a los pies de los apóstoles $(4,34.35)$. En la comunidad habia creyentes que tenian "posesiones, bienes, campos y casas", 
pero todo lo tenían en común, sea porque nadie consideraba como algo propio lo que tenf́a o porque todo lo vendían. Había, por lo tanto, comunidad de bienes: propiedades que no se vendían, pero que eran de lodos o el dinero de las propiedades que se vendían; (b) se repartía a cada uno según su necesidad $(2,45$ y 4 , 35), y (c) no había ningún necesitado entre ellos $(4,34)$.

Mucho se ha escrito sobre esta práctica de la koinonia de las primeras comunidades. Creo que es imposible reconstruir la organización económica y administrativa de csita vida en común, sobre todo si se considera el número de la comunidad: $3,000(2,41)$, después $5,000(4,4) \mathrm{y}$, finalmente "una multitud de hombres y mujeres $(5,14)$. Pero creo que lo más importante no es conocer la organización concreta de la koinonía, sino el espíritu de dicha organización. Y esto está claro en el texto: cada cual daba según su posibilidad, cada cual recibra según su necesidad y no había ningún necesilado entre ellos.

Lo más importante es lo último: la ausencia de necesitados o pobres entre ellos. Ese era, en definitiva, el objelivo de toda la práctica de la koinonía, aunque no sepamos el detalle de su organización concreta. Se compartía todo para que nadie tuviera necesidad. Este es el espíritu de la primera comunidad, normativo para todos los tiempos, aunque la forma económica y administrativa concreta no la conozcamos, ni sepamos sobre su éxito o fracaso posterior.

(3) Eran perseverantes en la fracción del pan y en las oraciones $(2,42)$. La fracción del pan es aquí ciertamente la cucaristía. El texto agrega: "partían el pan por las casas y tomaban el alimento con alegría y sencillez de corazón". En las primeras comunidades la eucaristía se celebraba en la casa, en el contexto de una comida (cfr. Lc 22, 14-20; 24, 28-31; 1Cor 10, 16-17; 1Cor 11, 17-32). Era una comida con Jesús resucitado, donde se celebraba la Ilegada del reino y se participaba en la comunión con el cuerpo y la sangre de Cristo. El espacio de la casa era el espacio de la comunidad cristiana, diferente al espacio del templo.

La didajé, la koinonia y la eucaristia son las tres actividades fundantes de la comunidad después de pentecostés, en las que perseveraban todos los discípulos de Jesús. Son tres actividades que tienen como contexto fundamental la casa, es decir, un espacio interno y más bien privado. Pero en los tres sumarios se destaca también la actividad pública de los apóstoles, cuyo espacio fundamental es el teinplo de Jerusalén.

(4) Los apóstoles realizaban muchos prodigios y señales $(2,43)$. Este tema se desarrolla en el segundo sumario, "los apóstoles daban testimonio con gran poder de la resurrección del Señor Jesús" $(4,33)$, y en el tercero $(5,12 a .15-16)$. La comunidad acompaña a los apóstoles (2, 46a y 5, 12b-14) -por el contexto, al templo-, donde se reúne todo el pueblo de Israel. Los apóstoles continúan, en Jerusalén y después de la resurrección, la práctica poderosa de Jesús. Dios está con cllos, así como estaba con Jesús. Es una práctica liberadora, en función de 
la construcción del reino de Dios. Lo importante aquí no es el carácter milagrero de la práctica de los apóstoles, sino el poder de Cristo resucitado y del Espíritu que se revela en la práctica de los apóstoles.

Con este sumario termina el relato sobre la constitución de la comunidad en Jerusalén (1, $12-2,47)$; ahora pasamos a la segunda parte, donde Lucas relata la manifestación de la comunidad en Jerusalén $(3,1-4,31)$. Véase la estructura general de 1, 12-5, 42: La Iglesia de Jerusalén. (Continuará.) 